\title{
COMPAÑEROS, A LAS ARMAS: COMBATIENTES CHILENOS EN CENTROAMÉRICA (1979-1989)*
}

\author{
Cristián Pérez \\ Centro de Estudios Públicos (CEP)
}

\begin{abstract}
Resumen: Esta presentación describe la historia de hombres y mujeres chilenos que se graduaron como oficiales en las escuelas militares de Cuba y otros Estados comunistas, que batallaron en la revolución nicaragüense, en la guerrilla salvadoreña, y regresaron a Chile para luchar contra Pinochet. El texto muestra las estrechas relaciones de la izquierda chilena con Cuba y otros gobiernos al este de la "cortina de hierro" que les permitieron dotarse de un contingente de militares con experiencia en combate durante las últimas décadas de la Guerra Fría.

Palabras clave: insurgencia, guerra fría, MIR, GAP, MAPUOC, FPMR, MR, PS Chile, PC Chile, Augusto Pinochet (atentado), Cuba, Centroamérica, URSS, gobierno militar (Chile), ELN-B, FSLN, FMLN, FAL.
\end{abstract}

Recibido: noviembre 2012; aceptado: enero 2013.

Cristí́n Pérez. Licenciado y (C) magister en Historia, Universidad de Santiago (Chile). Investigador del Centro de Estudios Públicos (CEP). Dirección electrónica: cristianpi@hotmail.com.

* Texto presentado en las III Jornadas Internacionales de Problemas Latinoamericanos: Movimientos Sociales, Estados y Partidos Políticos en América Latina, ((re)configuraciones Institucionales, Experiencias de Organización y Resistencia), Universidad Nacional de Cuyo, Mendoza, Argentina, del 28 al 30 de noviembre de 2012 . 


\section{COMRADES, TO ARMS! CHILEAN COMBATANTS IN CENTRAL AMERICA (1979-1989)}

Abstract: This article narrates the story of Chilean men and women who graduated as soldiers from the military schools in Cuba and other Communist states, who fought in the Nicaraguan revolution, in the Salvadoran civil war, and who returned to Chile to fight against Pinochet. The article shows the close relations between the Chilean left, Cuba, and other governments behind the "Iron Curtain", which endowed the Chilean left with a contingent of military officers experienced in combat during the last decades of the Cold War.

Keywords: insurgency, cold war, MIR, GAP, MAPUOC, FPMR, MR, PS Chile, PC Chile, Augusto Pinochet (assassination attempt), Cuba, Central America, URSS, military goverment (Chile), ELN-B, FSLN, FMLN, FAL.

Received: November 2012; accepted: January 2013.

\section{Introducción}

F rontera de Nicaragua y Costa Rica, noche de lluvia de junio de 1979. Nada se ve, pero las explosiones hacen saber a los militares chilenos que han llegado a la guerra. Al día siguiente los conducen a un claro del bosque y a la voz de ¡firmes! un guerrillero de mediana estatura y voz gruesa se presenta diciendo: "Soy Edén Pastora, Comandante Cero, jefe del Frente Sur Benjamín Zeledón"1. Después de una breve arenga, entrega los destinos: un grupo pequeño es enviado a la defensa antiaérea (artillería antiaérea); el resto se divide en dos, la mitad para los cañones y la otra para morteros ${ }^{2}$. De ese modo, cerca de un centenar de militares chilenos empiezan la lucha en la revolución nicaragüense. Están allí para cumplir el compromiso revolucionario originado hace años en una isla del mar Caribe. Ésta es su historia.

Los nombres entre comillas simples son los nombres de batalla o chapas de los internacionalistas, y los nombres entre comillas simples y cursivas han sido inventados para encubrir algunas identidades. Todas las entrevistas citadas pertenecen al archivo del autor.

${ }^{1}$ Pedro Barrios, "Con el Brazalate Rojingero", parte I, 2005. El Frente Sur Benjamín Zeledón fue la más importante estructura armada del Frente Sandinista de Liberación Nacional (FSLN). Su nombre recuerda a un líder político liberal de comienzos del siglo XX.

${ }^{2}$ Ibídem. 


\section{1. "Una Revolución ha de saber defenderse"3}

El golpe militar del 11 de septiembre de 1973 puso en tela de juicio la estrategia del Partido Comunista de Chile (PC) y del Partido Socialista de Chile (PS) para realizar la revolución. Quedó cuestionada la "vía pacífica" comunista que postergaba indefinidamente la lucha armada para acceder al poder; también fue jaqueada la ambigua línea del Partido Socialista, que desde el congreso de Chillán (1967) proponía pasar a acciones más radicales, pero que en la práctica se había traducido mayormente en el auspicio de la vía electoral.

Ante el golpe militar del 11 de septiembre los comunistas pasaron a la clandestinidad sin ofrecer resistencia, y las unidades armadas del PS, como el GAP (escolta de Allende), combatieron defendiendo La Moneda y la casa presidencial de Tomás Moro, y el "Aparato" (aparato militar) se enfrentó con tropas golpistas en el surponiente de Santiago (Indumet, La Legua). Fue evidente que los principales partidos de izquierda no contaban con capacidad armada para enfrentar esa coyuntu$\mathrm{ra}^{4}$.

En 1974 el PC, impulsado por los postulados de Boris Ponomariov, quien al analizar los sucesos del golpe en Chile concluye que las revoluciones deben saber defenderse y tener flexibilidad para cambiar de la vía pacífica a la armada ${ }^{5}$, y siguiendo las recomendaciones de sus grupos de estudio en la República Democrática Alemana y las declaraciones de importantes dirigentes en el exilio, se abre a la formación de oficiales militares en Cuba y en otros países socialistas, con el objetivo de dotarse de un contingente para democratizar las Fuerzas Armadas - percibidas como el sostén de la dictadura, con una nítida concepción de casta hereditaria - cuando regresara la democracia ${ }^{6}$.

${ }^{3}$ Boris Ponomariov, "Conferencia", 1974.

4 Patricio Quiroga, "Compañeros, el GAP: La Escolta de Allende", 2001; Cristián Pérez, "Salvador Allende, Apuntes sobre su Dispositivo de Seguridad: El Grupo de Amigos Personales (GAP)", 2000.

${ }^{5}$ Boris Ponomariov, "Conferencia”, 1974.

${ }^{6}$ Para seguir las discusiones de este período véanse las declaraciones del Partido Comunista de Chile "El Ultraizquierdismo, Caballo de Troya del Imperialismo" (1975), “Al Partido y al Pueblo de Chile” (1974), así como Viviana Bravo, "Moscú-La Habana-Berlín, los Caminos de la Rebelión: El Caso del Partido Comunista de Chile 1973-1986", 2007, Rolando Álvarez, Desde las Sombras: Una Historia de la Clandestinidad Comunista (1973-1980), 2003, y Volodia Teitelboim, Noches de Radio (Escucha Chile) Una Voz Viene de Lejos. 
Hacia 1974 el Partido Socialista estaba más adelantado que el PC en la formación de gente con conocimientos militares, pese a que esa preparación no había sido una política institucional. A mediados de los años 60 varios jóvenes encabezados por Elmo Catalán viajan a Cuba para realizar entrenamientos guerrilleros, y después constituyen el ala chilena del Ejército de Liberación Nacional de Bolivia (ELN-B) ${ }^{7}$. Poco tiempo después otros socialistas van a la isla para recibir entrenamiento militar rural, y al regreso forman la "Organa" para radicalizar al campesinado $^{8}$. A fines de julio de 1973, unos 30 militantes socialistas se trasladan a Cuba para entrenarse en técnicas de seguridad e integrarse al GAP a su vuelta; allí los encuentra el golpe del 11 de septiembre ${ }^{9}$. Ese día, poco después de las 12 horas los instructores cubanos les cuentan de la situación en Chile y los conducen al polígono donde comienzan a disparar con todas las armas disponibles para descargar la rabia contenida; a media tarde les dicen que Allende ha muerto y que el panorama es incierto porque desde el sur el general Prats avanza con la división de Concepción. Ellos creen que el regreso a Chile para luchar contra los golpistas es inminente, pero no se concreta en el corto tiempo. Parte de estos jóvenes permanecen en entrenamientos militares durante varios años y en distintos lugares, convirtiéndose en los mejores cuadros armados socialistas ${ }^{10}$. Entre ellos se encuentran David Camú, que encabezará a los socialistas en la guerra de Nicaragua, y 'El Osito', que en Europa ejercerá como escolta de importantes dirigentes de la organización.

Seis o siete meses después, durante el primer semestre de 1974, llega a La Habana Carlos Altamirano, secretario general del PS, que

Tomo I., 2001. Asimismo, para conocer los análisis soviéticos de este período, en especial los realizados por el Instituto de Marxismo-Leninismo del Comité Central del Partido Comunista de la URSS, véase Olga Uliánova, "La Unidad Popular y el Golpe Militar en Chile: Percepciones y Análisis Soviéticos”, 2000, pp. 114 y ss.

${ }^{7}$ Véase Cristián Pérez, "El Ejército del Che y los Chilenos que Continuaron su Lucha", 2003.

${ }^{8}$ Véase Cristián Pérez, "Guerrilla Rural en Chile: La Batalla del Fundo San Miguel, 1968", 2000a.

${ }^{9}$ Cristián Pérez, "Salvador Allende, Apuntes Sobre su Dispositivo de Seguridad: El Grupo de Amigos Personales GAP”, 2000b.

10 'El Osito', entrevista con el autor, Berlín, abril 2006; 'Galindo', entrevista con el autor, Valparaíso, octubre 2006; 'Juan Miranda', entrevista con el autor, Suecia, julio 1999. 
ha logrado salir de Chile apoyado por la seguridad de la RDA ${ }^{11}$. Una mañana se traslada hasta Santa María del Mar, donde en una residencia lo esperan los militantes que desde julio del año anterior se entrenan en Cuba. La conversación versa sobre las posibilidades de continuar con una formación militar de mayor nivel, que sería necesaria cuando volvieran a Chile a combatir a Pinochet, cuestión que aparece como una difusa opción. El grupo se divide: algunos pasan a la vida civil integrándose a la sociedad cubana, varios se van al MIR y pocos seguirán la carrera militar como socialistas ${ }^{12}$.

En abril de 1975, en la celebración del aniversario del PS, el comandante Manuel Piñeiro ('Barbarroja'), responsable del Departamento América del Partido Comunista de Cuba, después de abogar por la concreción de un frente antifascista en Chile, argumenta en el sentido de la necesaria preparación para luchar, porque “(...) el éxito del movimiento revolucionario dependerá de la medida en que las vanguardias dominen todas las formas de lucha y estén preparadas para la más rápida sustitución de una forma por otra, en dependencia de los cambios que se produzcan en la realidad. Compañeros chilenos: en nombre de nuestro Partido, quiero ratificarles que en esos empeños [dominar todas las formas de lucha], hoy más que nunca pueden contar con nuestra solidaridad activa y militante" 13 . Con ese discurso, desde las más altas esferas del poder cubano se legitimaba la formación de militares profesionales.

Lo más probable es que en una de las reuniones de Altamirano con Fidel Castro éste ofreciera cupos para la formación de oficiales militares en las Fuerzas Armadas Revolucionarias (FAR), y el líder del Partido Socialista aceptara.

El reclutamiento queda a cargo de 'El Indio', un antiguo dirigente sindical que había pertenecido al ELN-B en los años 60, y que era de absoluta confianza del partido y de la seguridad cubana. En el mayor secreto, en una habitación del cuarto piso del Hotel Habana Libre especialmente adaptada, son citados los postulantes. En la entrevista, con una carpeta con sus antecedentes a la vista, 'El Indio' les pregunta

11 Salazar, Gabriel, Conversaciones con Carlos Altamirano: Memorias Críticas, 2010, p. 381.

12 'El Osito', entrevista con el autor, Berlín, abril 2006; 'Juan Miranda', entrevista con el autor, Suecia, julio 1999.

${ }^{13}$ Luis Suárez (editor), Manuel 'Barbarroja' Piñeiro: Che Guevara y la Revolución Latinoamericana, 2006, p. 205. 
si quieren formar parte de las FAR y convertirse en oficiales militares. Uno de ellos, Juan Carlos Prado, es rechazado por haber hecho el servicio militar obligatorio en la Armada chilena, y tal vez porque su historia tenía alguna incoherencia ${ }^{14}$, y veinte son aceptados.

Así, en marzo de 1975, veinte militantes (hombres y mujeres) del Partido Socialista de Chile ingresan a las escuelas militares cubanas para iniciar la carrera de oficiales ${ }^{15}$. Al año siguiente un grupo compuesto por seis jóvenes ingresa a un regimiento en Bulgaria para formarse como oficiales de ese ejército ${ }^{16}$. Y entre 1975 y 1976 siete militantes, que ya tenían experiencia militar, entre los que se encuentran 'El Indio' y dos ex miembros de la 'Organa', se trasladan hasta Moscú para recibir formación como oficiales superiores. Este programa es de tal nivel que para graduarse deben coordinar un ejercicio donde participan el ejército, la marina y la aviación soviéticos ${ }^{17}$. El curso fue de nueve meses de duración y, "según comentó la dirección del PSCh, permitió mejorar considerablemente el trabajo del partido en esa área"18. Poco más adelante, el 29 de diciembre de 1976, Carlos Altamirano pedía a los responsables soviéticos un nuevo curso militar para 15 integrantes del PS. El 30 de diciembre de ese año, en una resolución del Secretariado del Comité Central del Partido Comunista de la Unión Soviética, se satisfacía "la solicitud del Secretario General del Partido Socialista de Chile camarada C. Altamirano y [se aceptaba] recibir en la URSS en 1977 a un grupo de representantes del PSCh en cantidad de 15 personas para que realicen el curso de preparación militar por un período de 11 meses. La recepción, abastecimiento material, organización de cursos y el pago del pasaje para el grupo entre Santiago y Moscú de ida y vuelta [se debe] encargar al Ministerio de Defensa de la URSS"19. Es probable que otros jóvenes socialistas hayan recibido entrenamiento en la RDA y en Rumania. En los años siguientes todos estos hombres y mujeres serán considerados los cuadros estratégicos del Partido Socialista chileno.

${ }^{14}$ Prado, Juan Carlos, entrevista con el autor, Santiago, mayo 2009.

15 Pascale Bonnefoy M., Claudio Pérez S. y Ángel Spotorno, Internacionalistas: Chilenos en la Revolución Popular Sandinista, 2009, p. 10.

16 'Reinaldo', entrevista con el autor, Buenos Aires, octubre 2011.

${ }^{17}$ Hernán Coloma, Los Tránsfugas, 2010, pp. 292-300.

18 Olga Uliánova, "La Unidad Popular y El Golpe Militar en Chile: Percepciones y Análisis Soviéticos”, 2000, p. 146.

${ }^{19}$ Ibídem, pp. 146-148 (destacado en el original). 
Por su parte, en junio de 1974 llegan a Cuba dirigentes del Partido Comunista para entrevistarse con los mandatarios del país. En la cita, la dirección acepta el ofrecimiento para iniciar la formación de oficiales militares de las distintas armas de un ejército convencional ${ }^{20}$. Orel Viciani, entonces importante dirigente del PC en La Habana y uno de los encargados de seleccionar a quienes ingresarían a la carrera militar, señala que el objetivo era contar con un contingente de oficiales para democratizar las Fuerzas Armadas chilenas ${ }^{21}$. "Recuerdo que Rodrigo Rojas, miembro de la dirección del partido, nos dijo: 'ustedes serán los futuros generales del Ejército chileno"”22. “(...) Se estaban formando cuadros oficiales [en Cuba], y en otros países socialistas, pero eran cuadros que se estaban formando — según se lo escuché al propio compañero Fidel Castro- para la eventualidad de que en Chile se produjera la derrota de la dictadura, mediante un proceso unitario que involucra a la Unidad Popular y a otras fuerzas, y entre ellas la Democracia Cristiana" 23 .

Entonces, la formación de oficiales comunistas chilenos en las escuelas militares cubanas comienza en 1975, denominándose 'la tarea' ${ }^{24}$. Entre el 15 y 16 de abril en La Habana es convocado un grupo de hombres y mujeres que estudian la carrera de medicina. En su mayoría son de origen proletario y campesino pobre. La edad promedio es 20 años y cursan entre segundo y cuarto año. En la reunión los dirigentes comunistas les plantean la misión de retirarse de sus estudios de medicina e incorporarse a las FAR para recibir formación de oficial regular ${ }^{25}$. Entre los estudiantes se encuentran, entre otros, Days Huerta, quien después morirá en combate en Nicaragua; Roberto Lira, fallecido en una emboscada en El Salvador ${ }^{26}$. Entonces, desde el 16 de abril de 1975,

${ }^{20}$ Javier Ortega, "La Historia Inédita de los Años Verde Olivo", La Tercera, serie especial, capítulo I, Santiago, 22 de abril de 2001.

${ }^{21}$ Orel Viciani, entrevista con el autor, Santiago de Chile, junio 2011.

22 Expresiones de Germán Cordobés (probablemente sea un seudónimo), oficial internacionalista. En Raúl Blanchet Muñoz, "En Qué Están los Combatientes de Ayer. A 25 Años del Surgimiento del Frente Patriótico Manuel Rodríguez", 2008, p. 12.

${ }^{23}$ Guillermo Teillier, “G. Teillier Sobre Combatientes Internacionalistas Chilenos", 27 de abril de 2006.

${ }^{24}$ Galvarino Melo, Piel de Lluvia, 2005, p. 134.

25 Germán Cordobés, “A 30 Años del Inicio de la Tarea Militar: 16 de Abril Día del Combatiente Internacionalista”, 2005.

${ }^{26}$ Ibídem. 
" 28 comunistas chilenos ingresan a la Escuela Militar Camilo Cienfuegos en La Habana para prepararse como especialista en artillería terrestre. Otros 29 iniciaron especialización en tropas generales en la Escuela General Antonio Maceo, en las afueras de la capital cubana"27.

En los años siguientes, desde todas partes del mundo decenas de militantes comunistas concurrieron al llamado de las armas. En su mayoría estos jóvenes habían partido al exilio junto a sus padres y aceptaron prepararse para hacer su aporte en la larga lucha, para liberar a su patria $^{28}$. Entre los que llegaron a Cuba desde otros países se encuentran: Edgardo Javier Lagos, que falleció en Costa Rica por las heridas sufridas en la guerra en Nicaragua, y Raúl Pellegrin, quien más adelante se convertirá en el líder del Frente Patriótico Manuel Rodríguez (FPMR). Al grupo de estudiantes de medicina y a los jóvenes exiliados se sumaron ex presos políticos expulsados de Chile, como Sergio Apablaza ${ }^{29}$, quien durante el gobierno de la Unidad Popular había sido dirigente estudiantil en el Pedagógico de la Universidad de Chile, detenido por la DINA pasó un año desaparecido, fue torturado y expulsado del país. Tras unos meses en Panamá arribó a Cuba ${ }^{30}$. Allí se convirtió en uno de los más importantes cuadros militares.

En el Pleno del Comité Central del Partido Comunista de agosto de 1977, realizado en las afueras de Moscú, por vez primera participó uno de los militantes que recibían instrucción en las escuelas militares. En una de las reuniones, 'Gave' "desde el fondo de la sala avanzó hacia la Presidencia de la Asamblea, se cuadró como militar y, dirigiéndose a mí, habló también como militar. Dijo: ‘CCompañero Secretario General, permiso para dirigirle la palabra al Pleno!'. Fue ese un momento emocionante" $" 31$.

${ }^{27}$ Pascale Bonnefoy M., Claudio Pérez S. y Ángel Spotorno, Internacionalistas: Chilenos en la Revolución Popular Sandinista, 2009, p. 11.

${ }^{28}$ Versiones de este proceso pueden leerse en Javier Ortega, "La Historia Inédita de los Años Verde Olivo", La Tercera, serie especial (capítulo I), Santiago, 22 de abril de 2001.

${ }^{29}$ Germán Cordobés, “A 30 Años del Inicio de la Tarea Militar: 16 de Abril día del Combatiente Internacionalista”, 2005.

${ }^{30}$ Adriana Meyer, "En Política Todo es Posible. Entrevista con Sergio Apablaza Guerra, ex Jefe del Frente Patriótico Manuel Rodríguez”, 24 de diciembre de 2007.

${ }^{31}$ Luis Corvalán L., De lo Vivido y lo Peleado. Memorias, 1997, p. 249. 
Los jóvenes militares comunistas y socialistas “(...) se formaron en las Academias Superiores de La Habana, en las especialidades de: infantería mecanizada, artillería, blindados, sistemas de defensa antiaéreos, comunicaciones, logística, medicina militar, zapadores (...)"32. Esta formación fue complementada con cursos militares en Bulgaria, hasta donde se trasladan algunos campesinos que antes del golpe fueron enviados por la Confederación Campesina e Indígena 'Ranquíl' a realizar cursos de tractoristas en la Unión Soviética ${ }^{33}$. Es probable que en otros países como la RDA y Rumania también se hayan formado militares comunistas chilenos.

Lo verdaderamente importante de esta política de formación de cuadros es que los gobernantes de Cuba y de otros países socialistas promueven la integración de chilenos (socialistas y comunistas) a sus ejércitos, lo que da cuenta de la confianza que tenían con una parte de la izquierda chilena.

Los socialistas se forman militarmente esperanzados en que su dirección cumpla la vaga promesa de reingresarlos a Chile para combatir a Pinochet; y los comunistas esperan que una vez derrotada la "dictadura fascista militar", puedan retornar al país e integrarse al nuevo ejército chileno democrático.

\section{Bajo las granadas de la Guardia Nacional}

Hacia fines de 1977 en la zona sur de Nicaragua se ha constituido una poderosa fuerza militar del Frente Sandinista de Liberación Nacional, conocida como Frente Sur Benjamín Zeledón. En sus filas combate Patricio Arenas, militante del Partido Socialista chileno, que había comenzado en 1974 como ayudista y luego se incorporó a la guerrilla. $\mathrm{Al}$ año siguiente doce chilenos estaban luchando como voluntarios del Frente Sandinista; destacaban entre ellos los militantes del MIR Daniel Torres, Mario Guerra, Juan Cabezas y 'Bernardo', un ex preso político mirista de San Antonio; 'Guido' y 'Carmen', que ya no militaba en el MIR; 'Emilia', una antropóloga sin militancia; 'Alonso', 'Gabino' y el

\footnotetext{
${ }^{32}$ Galvarino Melo, Piel de Lluvia, 2005, p. 134.

33 'Tato', conversación con el autor, Santiago de Chile, junio 2009.
} 
fotógrafo Haroldo Horta Tricallotis, quien llegó a tomar fotografías de la guerrilla y luego se unió a ésta ${ }^{34}$.

Un año después, a mediados de 1979, cuando el Frente Sandinista inicia la ofensiva final, advierte que no podrá vencer si no cuenta con personal especializado en el manejo de artillería ligera y morteros para la guerra convencional que han diseñado en el sur del país. Para concretar esta idea piden ayuda a Cuba. Como respuesta, el 9 de junio de 1979, los oficiales militares comunistas y socialistas son convocados separados por partido a presentarse en el Estado Mayor del Ejército Occidental. Luego son llevados a una academia para oficiales donde se les agregan ocho uruguayos, y un par de días después llegan las mujeres oficiales médicos militares ${ }^{35}$. ¿De qué se trata?

La incógnita se reveló un domingo cuando el grupo es reunido en la Academia de Guerra. Por la noche arriba el Comandante en Jefe. "En la pizarra de un salón, Castro trazó con tiza el futuro de los chilenos. Un mapa de Nicaragua (...) Fidel les explicó que los sandinistas necesitaban artillería y que Cuba no iba a intervenir directamente. Los chilenos todavía recuerdan la sugerencia que siguió a la explicación: 'Yo he pensado que ustedes vayan"'36. En esos días José Valdivia y Javier Pichardo, importantes jefes del Frente Sur del FSLN, se encuentran en Cuba pidiendo artilleros, se reúnen con los chilenos y les hablan de la revolución en Nicaragua y de la situación estratégica de la guerra de liberación nacional ${ }^{37}$.

Las autoridades cubanas transmiten la petición a Luis Corvalán, que reside en Moscú, porque es quien debe autorizar la participación de los militantes comunistas. El tiempo apremia. Poco después de la medianoche el comandante Castro retorna a la Academia de Guerra. “"Nos dijo que iba camino a su casa y había recibido la respuesta de Corvalán y pensó que la noticia no podía esperar', relata uno de los ‘combatientes'. El viaje a Nicaragua estaba acordado"38. Con seguridad

${ }^{34}$ Pascale Bonnefoy M., Claudio Pérez S. y Ángel Spotorno, Internacionalistas: Chilenos en la Revolución Popular Sandinista, 2009, p. 12.

35 Ibídem, p. 11.

${ }^{36}$ Pablo Vergara y Sebastián Campaña, "FPMR: El Fantasma sin Cabeza", Siete $+7 \mathrm{~N}^{\mathrm{o}} 24$, agosto 2002, p. 47.

37 José Valdivia ('Marvin'), coronel del Ejército Popular Sandinista (EPS), entrevista con el autor, Managua, Nicaragua, octubre (2008).

38 Pablo Vergara y Sebastián Campaña, "FPMR: El Fantasma sin Cabeza", Siete $+7 \mathrm{~N}^{\mathrm{o}} 24$, agosto 2002, p. 48. 
un petitorio similar fue hecho a los jefes de los dos partidos socialistas (Altamirano, Almeyda) ${ }^{39}$, al Movimiento de Acción Popular UnitariaObrero Campesino (MAPU-OC) y a otras organizaciones políticas latinoamericanas. En definitiva, el PC, los dos grupos PS y el MAPU-OC aceptan. El MAPU-OC selecciona un pequeño contingente de militantes entre los que se cuentan "el compañero Barros, Hugo, Rosa, Bruno, Juan Carlos, Pablo, Emilio, el chueco Víctor, [eran] abogados, ingenieros, odontólogos (..." $)^{\natural 40}$.

Los chilenos en Nicaragua son poco menos de cien. Los comunistas quedan a cargo de Sergio Apablaza ('Salvador'), y los socialistas al mando de David Camú y 'Miguel'. Otros camaradas que no son elegidos para viajar, porque no son artilleros o cumplen otras tareas, son enviados a entrenamientos en Cuba por si fuera necesario su traslado a Nicaragua ${ }^{41}$. El contingente es acompañado por doce cubanos pertenecientes a las Tropas Especiales e Inteligencia. Entre ellos: Antonio de la Guardia, Alejandro Ronda, Juan Guillermo Pérez, Fernando Comas y Renán Montero ${ }^{42}$.

El número de milicianos chilenos parece significativo, pues representa poco más del 10\% de las fuerzas del Frente Sur, pero a diferencia de los sandinistas, en su mayoría son militares con una acabada formación profesional.

Los primeros soldados chilenos que arriban a la zona de guerra en el sur de Nicaragua en junio de 1979 son cuatro oficiales artilleros pertenecientes al Partido Socialista llamados: Pedro Hernández, Fran-

39 El Partido Socialista de Chile se dividió en los primeros meses de 1979, cuando el Secretario General, Carlos Altamirano, fue expulsado por el Comité Central clandestino. Altamirano trasladó sus oficinas a París, y continuó dirigiendo una parte de la organización. Lo acompañaron, entre otros, Jorge Arrate y Ricardo Núñez. El otro sector mantuvo sus instalaciones en la RDA, asumiendo como secretario general Clodomiro Almeyda, junto con Rolando Calderón, Hernán del Canto, Camilo Escalona, María Elena Carrera y los dirigentes clandestinos.

${ }^{40}$ Ismael Llona Mouat, Los Santos Están Marchando, 2006, p.163. Llona era el encargado del MAPU-OC en La Habana y participó en la selección de combatientes para la guerra en Nicaragua.

${ }^{41}$ Relato de 'Manuel', integrante del GAP, en entrevista con el autor, Santiago de Chile, septiembre 2006. Él participó en ese proceso, pero no alcanzó a viajar a Nicaragua.

${ }^{42}$ Humberto Ortega Saavedra (general), La Epopeya de la Insurrección, 2004, p. 398. 
cisco del Río ('Antonio') ${ }^{43}$, 'Leonardo' y Manuel Reyes. Ellos le dan forma a las primeras baterías de cañones y morteros. Con su llegada la lucha cambia su fisonomía transformándose en una "típica guerra regular con líneas definidas, con la modalidad de la Guerra de movimientos, combinando el accionar de agrupaciones numerosas con las acciones de unidades menores, que operan en la clásica guerra de guerrillas", sostiene Humberto Ortega, jefe del Estado Mayor Santinista ${ }^{44}$.

Pocos días después de la llegada de los primeros artilleros arriba un grupo de treinta hombres, de los cuales seis son chilenos, los que por su nivel de especialización en el uso de medios artilleros terrestres y antiaéreos estaban subordinados directamente al Estado Mayor del Frente $\mathrm{Sur}^{45}$. "Si bien es cierto [que] la unidad fundamental [en que combaten los chilenos] estaba constituida por la artillería, muchos de nuestros compañeros fueron derivando en otras especialidades con distintas tareas. Algunos junto a los jefes de las columnas guerrilleras, como fue el caso de Raúl Pellegrin (...) del Mago; del Pope; del Indio; del Huguito; del Paloma; y del Marilao (...) Otros, como Germán, estaban en la instrucción al frente de una escuela que funcionó en plena zona de combate. O como el Nene, que aportó su experiencia de tornero en la reparación de armamento. También otros, por la necesidad de la lucha, estuvieron en la defensa antiaérea como el Loco Lira, Vasili y Ricardo (...). Al frente de las pequeñas unidades formadas por uruguayos, salvadoreños, guatemaltecos y nicaragüenses se encontraban, entre otros, Roberto Nordenflycht (...) el Gave; Gladio; Joaquín; el Lagarto; el Chino; José, y otros hermanos socialistas, y por cierto, Days Huerta (...)"46. Otros militares participan en las tareas de aseguramiento combativo, en los aspectos médicos en la primera línea de batalla, algunos aportan en el trabajo de información, como 'Jorge', un socialista que cayó después; y en la conducción del Estado Mayor del Frente Sur participan el Patán, el Cabezón y Antonio ${ }^{47}$. El ex coronel sandinista José Valdivia cuenta que uno de los chilenos, del que no recuerda su nombre, se desempeñó

${ }^{43}$ Pascale Bonnefoy M., Claudio Pérez S. y Ángel Spotorno, Internacionalistas: Chilenos en la Revolución Popular Sandinista, 2009, p. 12.

${ }^{44}$ Humberto Ortega Saavedra (general), La Epopeya de la Insurrección, 2004, p. 415.

45 Sergio Apablaza Guerra, "Recordando a un Hermano", 2005.

${ }^{46}$ Ibídem.

${ }^{47}$ Ibídem. 
como asesor del Estado Mayor, y había pertenecido a la guardia del Presidente Allende, siendo sumamente competente en ese puesto ${ }^{48}$. Se trata de Manuel Cortés ('Miguel', 'Patán'), quien a poco de terminada la guerra fue asesor de Joaquín Cuadra, jefe de Estado Mayor del Ejército Popular Sandinista. Posteriormente Cortés formó parte de la policía sandinista donde ejerció una jefatura.

El 1 de julio de 1979, mientras las fuerzas sandinistas avanzan para tomar Sebaco, pierde la vida Days Huerta Lillo, que estaba destinado a la artillería, él murió cuando encontrándose en su posición cayó una granada que lo destrozó. Para sepultarlo, preparan una caja de municiones como ataúd, la que cubren con una bandera de Chile y otra del FSLN. Le montan una guardia y le rinden honores militares ${ }^{49}$. Del hecho existe una fotografía donde se aprecia una formación en honor al caído. En la primera fila puede verse a Sergio Apablaza, Juan Palavecino y 'Beatriz' una médico militar chilena. En la instantánea se ven marciales pese a no llevar el mismo uniforme, y los cabellos lucen largos y las barbas crecidas. Queda claro que se encuentran en el frente ${ }^{50}$. Pocos días después, el contingente sureño vuelve a vestir de luto, porque Edgardo Lagos Aguirre es herido por una granada de artillería, cuya esquirla le penetra por la cadera destrozándole el pulmón. Fue evacuado a Costa Rica donde, pese a la atención médica, falleció ${ }^{51}$.

En lo más álgido de la batalla, David Camú, uno de los mejores militares socialistas, está a cargo de una batería de morteros, uno de los cuales se traba con la bomba adentro; al darse vuelta instintivamente pasa la mano sobre la boca del mortero en el momento que el proyectil sale, cortándole la extremidad a la altura de la muñeca. 'René' con el cuchillo de combate le cercena el resto de tendones y músculos. Luego las doctoras se encargan de él ${ }^{52}$. Un par de meses después se le puede

48 José Valdivia, ('Marvin'), entrevista con el autor, Managua, octubre 2008.

${ }^{49}$ Hernán Vidal, Frente Patriótico Manuel Rodríguez: El Tabú del Conflicto Armado en Chile, 1995, pp.161-162.

${ }^{50} \mathrm{La}$ fotografía puede verse en Memoria Viva, viernes 21 de julio de 2006: http://memoriaviva.net/article.php3?id_article=295.

${ }^{51}$ Hernán Vidal, Frente Patriótico Manuel Rodríguez: El Tabú del Conflicto Armado en Chile, 1995, p. 162.

52 Luis Rojas N., De la Rebelión Popular a la Sublevación Imaginada: Antecedentes de la Historia Política y Militar del Partido Comunista de Chile $y$ del FPMR 1973-1990, 2011, p. 127. 
ver en Managua con su uniforme de camuflaje en la celebración de la puesta en marcha del Ejército Popular Sandinista.

El 18 de julio las fuerzas somocistas se desbandan ${ }^{53}$ y la victoria es del FSLN. "Habíamos triunfado y la Guardia Nacional huía despavorida, abandonando hombres y equipos en dirección al puerto de San Juan, donde algunas barcazas los esperaban. Vivíamos una fiesta. Risas y llantos, con la certeza de comenzar a construir el futuro" ${ }^{54}$. Obedeciendo la orden del Estado Mayor Sandinista de marchar hacia la capital un chileno relata: "Todos iban a Managua en migración masiva y loca. Nos encargamos de recoger todo el armamento, cargar camiones, asumir toda la responsabilidad, dejar gente y armamento en la retaguardia para cualquier eventualidad. Esto era lo más difícil porque nadie quería quedarse (...). Era un ambiente hermoso y conmovedor. Allí se producía un poco la insatisfacción de uno; a pesar de todo no se podía vibrar con la misma intensidad porque ese triunfo no era de nuestro pueblo. Todos los sandinistas se iban a su casa (...) Nosotros nos quedamos solos. Nos ubicamos donde pudimos, decididos a mantener nuestras unidades" $" 55$.

En una capital alterada con miles de personas en sus calles festejando la victoria, como se aprecia en todas las películas, videos y fotografías de la época ${ }^{56}$, el 20 de julio de 1979 ingresan a esa ciudad la Junta de Reconstrucción Nacional, la Dirección Nacional del Frente Sandinista y sus fuerzas, entre ellas las del Frente Sur Benjamín Zeledón ${ }^{57}$, donde orgullosos marchan decenas de combatientes chilenos. Han triunfado.

Contemplando los festejos con cierto sentimiento de frustración por no estar celebrando en las calles de Chile, circulan por la ciudad.

${ }^{53}$ Para entender cómo percibió ese desbande la Guardia Nacional, véase Justiniano Pérez, GN Versus FSLN: Análisis de un Pasado Reciente, 2008. Pérez fue oficial de la Guardia Nacional y el último jefe de la Escuela de Entrenamiento Básico de Infantería (EEBI).

54 Sergio Apablaza Guerra, "Nicaragua. Julio de 1979. Recuerdos del Triunfo Guerrillero", 2006.

55 Testimonio de un internacionalista chileno anónimo. Citado por Hernán Vidal en Frente Patriótico Manuel Rodríguez: El Tabú del Conflicto Armado en Chile. Santiago, 1995, p. 163.

56 "Siete Días" (programa en la televisión mexicana) (1979). "Revolución Sandinista. La Ofensiva Final" (Parte I). http://www.youtube.com/ watch? $\mathrm{v}=\mathrm{tP} 4 \mathrm{zpKRHIRA}$.

${ }^{57}$ Humberto Ortega Saavedra (general), La Epopeya de la Insurrección, 2004, pp. 437-438. 
Penetran al palacio de Somoza y recorren las oficinas de la policía política en cuyos archivos encuentran declaraciones y confesiones obtenidas bajo tortura. En un archivador descubren "una serie de documentos internos de la Guardia Nacional preparados en Chile por Carabineros, por ayudas bilaterales; cartas firmadas por el agregado militar chileno, cartas de personajes importantes, muchos testimonios de colaboración con las Fuerzas Especiales de Chile"58.

Asegurada la victoria los chilenos asumen nuevas tareas. La principal es la colaboración para la organización del Ejército Popular Sandinista. En la misión de constituirlo algunos se dedican a "la instrucción militar de carácter regular, y la organización de los aseguramientos. En particular, el control del armamento (...)"59. También organizan las escuelas militares sandinistas, donde se destaca Roberto Nordenflycht, quien consigue poner en funcionamiento los primeros blindados sandinistas ${ }^{60}$. Parte de los chilenos fue enviada a las principales regiones del país a organizar unidades militares. En la práctica "estas pequeñas unidades se formaron en el propio combate, pues la respuesta del imperio no se hizo esperar y armó e instruyó bandas destinadas a desestabilizar la revolución" 61. Éstas son conocidas como "contras"62. En los años siguientes, nuevos y viejos chilenos ayudarán a los sandinistas a combatirlas.

Para apoyar al gobierno recién instalado, entre otros, llega Juan Seoane, quien asesora en la formación de la policía sandinista. Seoane había sido jefe de la unidad escolta presidencial de la Policía de Investigaciones de Chile. El 11 de septiembre de 1973 combatió junto al Presidente Allende defendiendo La Moneda, fue detenido y enviado al Regimiento Tacna, y luego dado de baja de la policía. Se exilió en Ar-

${ }^{58}$ Hernán Vidal, Frente Patriótico Manuel Rodríguez: El Tabú del Conflicto Armado en Chile, 1995, pp. 164-165.

La colaboración entre las Fuerzas Especiales del Ejército chileno y la Escuela de Entrenamiento Básico de Infantería (EEBI) esta tratado por Eduardo Marenco, “Entrevista con 'El Chiguín': Los 'Gansos Salvajes' de la EEBI”, La Prensa 10 de agosto 2000.

${ }^{59}$ Sergio Apablaza Guerra, "Recordando a un Hermano", 2005.

${ }^{60}$ Ibídem.

${ }^{61}$ Ibídem.

62 Nombre que tenían los diversos grupos que combatían militarmente al gobierno sandinista. El más importante era la Fuerza Democrática de Nicaragua (FDN), organización financiada por la CIA que tenía sus bases en Honduras. Su jefe fue el coronel Enrique Bermúdez Varela. 
gentina, Cuba y México ${ }^{63}$. También arriban ex miembros de la Fuerza Aérea de Chile para formar la Fuerza Aérea Sandinista (FAS). Entre ellos sobresalen el capitán Raúl Vergara, que es uno de los tres primeros pilotos de guerra del naciente contingente aéreo nicaragüense, y los suboficiales Iván Figueroa y Enrique Villanueva, que como militantes del Partido Comunista llegaron a cumplir tareas revolucionarias. Ellos habían sido procesados y condenados por un consejo de guerra en su país en el proceso caratulado Bachelet y Otros. En Nicaragua Figueroa dio instrucción de paracaidismo ${ }^{64}$. Años después, Figueroa y Villanueva forman parte del FPMR, y en alguna época integran la Dirección Nacional del grupo. Figueroa desapareció en la "triple frontera" en los años 90 en un acontecimiento del que casi no se tienen noticias.

Según Luis Corvalán, al finalizar la guerra en Nicaragua existían 76 hombres del Partido Comunista, que habían alcanzado el grado de oficiales de las tropas sandinistas. Uno de ellos era asesor personal del comandante Humberto Ortega, jefe de las Fuerzas Armadas del país ${ }^{65}$.

Como fruto de la victoria los oficiales comunistas comienzan a sistematizar la experiencia para ponerla al servicio de la realidad chilena. “(...) Formamos un gran colectivo que periódicamente elaboraba propuestas e iniciativas pensando en nuestra lucha y al mismo tiempo desarrollaba ideas en correspondencia con las necesidades y responsabilidades de ser parte del Ejército Popular Sandinista"66. "Empezamos a vivir en función de la realidad chilena. El Partido Comunista nos tomó más en serio y dejó de vernos en la perspectiva original de que nos incorporáramos [a Chile] cuando todo estuviera resuelto [derrotado Pinochet] $]^{\prime 67}$

Poco después del triunfo revolucionario, los derrotados financiados por Estados Unidos dan forma a la oposición armada conocidas

${ }^{63}$ Véase Juan Seoane, Los Viejos Robles Mueren de Pie. Relato Autobiográfico de un Policía Leal (2009).

${ }^{64}$ Pascale Bonnefoy M., Claudio Pérez S. y Ángel Spotorno, Internacionalistas: Chilenos en la Revolución Popular Sandinista, 2009, p. 14.

${ }^{65}$ Qué Pasa, "La Cruzada Armada del PC", 23 de mayo de 1998). Nota 1. Conversación entre Friedl Trappen y Luis Corvalán en Moscú en septiembre de 1979, archivos del SED.

66 Sergio Apablaza Guerra, "Recordando a un Hermano", 2005.

67 Relato de Sergio Apablaza Guerra, en Virginia Vidal, "Qué Fue el Frente Patriótico Manuel Rodríguez: Le Debemos su Rescate Histórico", 2005). 
como "contra". Estas fuerzas guerrilleras inician operaciones en la frontera con Honduras y para combatirlas los sandinistas crean los Batallones de Lucha Irregular (BLI) y las Tropas Pablo Úbeda del Ministerio del Interior. En estas agrupaciones muchos internacionalistas chilenos combaten, y no pocos pierden la vida. Así, por ejemplo, los socialistas Alberto Geraldó y Juan Cortés, que habían recibido entrenamiento militar en la RDA, murieron en una emboscada de la "Contra" en 1982; el militante del Frente Patriótico Manuel Rodríguez, Luis Mendoza, cayó en 1987 en una emboscada; asimismo José Ibáñez murió en combate ese mismo año ${ }^{68}$.

Como ya vimos, después del triunfo sandinista una parte de los militares chilenos continúa en labores de asesoramiento en la formación del Ejército Popular Sandinista, otros vuelven a Cuba, algunos retornan a Europa y varios se trasladan hasta El Salvador para seguir la lucha revolucionaria.

Por esos años el frente Farabundo Martí para la Liberación Nacional (FMLN) ha aumentado su capacidad armada y sus acciones son cada vez de mayor envergadura. El 10 de enero de 1981 inician la primera "ofensiva final". Para apoyar este esfuerzo y entregar el componente más profesional en la planificación de las operaciones y en el adiestramiento de guerrilleros, los salvadoreños piden apoyo, y las organizaciones chilenas aceptan el desafío.

Así, la principal colaboración es entre los partidos comunistas de Chile y El Salvador. Por eso durante 1981 los chilenos participan en la elaboración de los planes operativos de las Fuerzas Armadas de Liberación (FAL) del PC salvadoreño, y también dan instrucción militar a mandos medios y dirigentes de ese partido ${ }^{69}$. En las FAL trabajan directamente con el actual diputado José Luis Merino, entonces 'Ramiro Vásquez' o simplemente comandante Ramiro, jefe de las FAL. Al poco tiempo y por su propia voluntad, Roberto Lira, dentista y militar graduado en Cuba, se integra a la guerrilla salvadoreña, y es también el primer chileno en morir en una emboscada en 1981. Años después,

68 Pascale Bonnefoy M., Claudio Pérez S. y Ángel Spotorno, Internacionalistas: Chilenos en la Revolución Popular Sandinista, 2009, pp. 15, 150153.

${ }^{69}$ Luis Rojas N., De la Rebelión Popular a la Sublevación Imaginada: Antecedentes de la Historia Política y Militar del Partido Comunista de Chile $y$ del FPMR 1973-1990, 2011, p. 145. 
cuatro oficiales comunistas se unen a la lucha, éstos son: 'Jerónimo' y 'Vladimir' de tropas generales, el 'Negro Alberto', artillero antiaéreo, y el ingeniero 'Javier' 70 .

Entre los socialistas destaca una ingeniera en telecomunicaciones graduada en La Habana, que empezó a trabajar con los salvadoreños en Nicaragua, para luego trasladarse a El Salvador e instalarse en Chalatenango en la comandancia del FMLN, donde trabajó en la Radio Farabundo Martí y como instructora en escuelas de telecomunicaciones que ella creo $^{71}$.

Es posible señalar que algunos chilenos, especialmente comunistas, se mantuvieron en la guerrilla hasta la segunda "ofensiva final", que comenzó el 11 de noviembre de 1989. Aunque no es posible saber a ciencia cierta el número de compatriotas que combatieron allí hasta 1989, sí se sabe de algunos que perdieron la vida. Entre los miembros del PC que fallecieron, además de Roberto Lira, se encuentran: Volodia Alarcón, que cayó en una emboscada en 1989; Víctor Otero, murió en la "ofensiva final" de 1989; Cristián Bascuñán, en la "ofensiva final" en noviembre de 1989. Entre los militantes del Partido Socialista caídos se cuentan: Charlo Reyes, quien murió en enero de 1983; Juan Palavecino que, al parecer, había realizado su entrenamiento militar en Rumania, cayó en la década de los 80 sin poder precisarse una fecha; y Juan Diez murió en combate en $1984^{72}$.

\section{Epílogo en el sur del mundo}

En 1980 la dictadura chilena, por medio de un plebiscito fraudulento, adopta una nueva Constitución ${ }^{73}$. Como respuesta el Partido Comunista da inicio a la Política de Rebelión Popular de Masas (PRPM). Para implementar los aspectos militares más especializados de la estrategia, a comienzos de 1983 ingresan oficiales que habían combatido en Centroamérica, quienes darán forma a las estructuras político-mil-

${ }^{70}$ Ibídem, p. 150.

${ }^{71}$ Ibídem, pp. 152-153.

72 Pascale Bonnefoy M., Claudio Pérez S. y Ángel Spotorno, Internacionalistas: Chilenos en la Revolución Popular Sandinista, 2009, pp. 150-153.

${ }^{73}$ La consulta se realizó sin registros electorales y la oposición sólo tuvo derecho a realizar un acto público en el que habló el ex Presidente Eduardo Frei Montalva. 
itares del partido: el Frente Patriótico Manuel Rodríguez (FPMR) y el Trabajo Militar de Masas o Milicias Rodriguistas (MR). Raúl Pellegrin es designado jefe del FPMR, que se constituye como la fuerza militar del Partido Comunista, y Sergio Apablaza es designado jefe de las Milicias Rodriguistas ${ }^{74}$.

El 14 de diciembre de 1983 el FPMR realiza un sabotaje a la electricidad que es su primera acción, y en los años siguientes materializa atentados a tendidos de luz, a puentes ferroviarios, a cuarteles de la policía secreta, a destacamentos policiales y militares ${ }^{75}$.

1986 es para el Partido Comunista el "año decisivo" para derrocar a la dictadura. Con el fin de estar preparada para esto, un año antes la organización estimó necesario “(...) conseguir el máximo de pertrechos, para un momento decisivo. Así fue que decidimos traer armas"76. Se inicia, entonces, un operativo internacional, que al año siguiente será conocido como Carrizal, cuyo objetivo era dotar al PC de una cantidad importante de armas industriales para concretar la sublevación nacional.

Para llevar a cabo una acción de tal envergadura, contaron con el apoyo de la Unión Soviética, Cuba y otros países. Por los chilenos, la dirección era de la Comisión Militar del $\mathrm{PC}^{77}$. El responsable designado fue 'Pedro', quien, según Televisión Nacional de Chile, es Orlando Bahamonde $^{78}$. En Nicaragua 'Pedro' había trabajado en la logística estratégica. Por parte de los cubanos no hay suficiente información, pero lo más probable es que participaran los hombres de Tropas Especiales encabezados por Alejandro Ronda.

Las armas son extraídas desde un mercante sin bandera ni matrícula (Río Najasa) en aguas internacionales por la goleta Chompalhue

${ }^{74}$ Para un pormenorizado relato de estos hechos véanse Cristóbal Peña, Los Fusileros. Crónica Secreta de una Guerrilla en Chile, 2007, Judith 'Tita' Friedman V., Mi Hijo Raúl Pellegrin: Comandante José Miguel, 2008.

75 Para tener idea de las acciones realizadas por el FPMR en esos años en un tono novelado, véase Ricardo Palma Salamanca, Una Larga Cola de Acero: (Historia del FPMR 1984-1988), 2001.

76 Relato de Guillermo Teillier, en Francisco Herreros, Del Gobierno del Pueblo a la Rebelión Popular, 2003, p. 527.

77 Véase documento elaborado por el grupo Reorganización del Rodriguismo, "Raúl Pellegrin y el Pensamiento del FPMR: Historia del FPMR", 1996 , p. 25.

78 Televisión Nacional de Chile, "Informe Especial”, capítulo del 28 de junio de 2006). 
comandada por el ingeniero Manuel Santana, sin mayores inconvenientes $^{79}$. En la zona de desembarque esperan un centenar de militantes, que cuando la nave llega se enteran de la misión, que se desarrolla con normalidad ${ }^{80}$. Meses después, a poco de realizar un segundo desembarco, son descubiertos y muchos participantes detenidos ${ }^{81}$.

Poco después, el domingo siete de septiembre de 1986 a las 18.31 horas un comando del FPMR, dirigido por el oficial militar formado en Bulgaria, que había combatido a la "Contra" en Nicaragua, José Joaquín Valenzuela Levi, realizó una emboscada para dar muerte a Augusto Pinochet. Pese a que logran destruir varios autos de la comitiva y dar muerte a cinco escoltas, y dejar numerosos heridos, el general salvó con vida ${ }^{82}$. Este episodio marcaría el ocaso de la Política de Rebelión Popular de Masas (PRPM) del PC chileno.

En 1987 los comandantes del Frente se independizan del Partido Comunista, al año siguiente adoptan una estrategia conocida como Guerra Patriótica Nacional, con la finalidad de superar la PRPM, y para inaugurarla el 21 de octubre de 1988 toman cuatro pueblos rurales. En operaciones de las fuerzas de seguridad después de la toma de Los Queñes, mueren Raúl Pellegrin, líder del FPMR, y su compañera Cecilia Magni $^{83}$. Así termina la historia del grupo formado por oficiales militares comunistas que habían tenido éxito en Nicaragua y que volvieron a Chile a luchar contra Pinochet.

Por su parte, desde 1982 el Partido Socialista de Almeyda ejecuta un plan de retornos clandestinos a Chile: "se rehizo en la clandestinidad la estructura territorial, se generaron múltiples acciones rupturistas, al calor de la lucha de masas, se organizaron unidades para acciones directas y se trabajó en la logística necesaria para una lucha en todos los frentes" $"$. Algunos militantes que ingresan al país han participado en la guerra de liberación de Nicaragua y en la guerrilla salvadoreña. Con ellos el PS-Almeyda forma un embrionario aparato armado llamado

${ }^{79}$ Manuel Santana, entrevista con el autor, Buenos Aires, octubre 2011.

${ }^{80}$ Patricio Ruilova, entrevista con el autor, Buenos Aires, octubre 2011.

${ }^{81}$ Manuel Santana, entrevista con el autor, Buenos Aires, octubre 2011.

82 José Joaquín Valenzuela Levi, ('Comandante Ernesto'), en “Otro Día Será”, 1987.

${ }^{83}$ Para un relato detallado de estos hechos véase Cristóbal Peña, Los Fusilero: Crónica Secreta de una Guerrilla en Chile, 2007.

${ }^{84}$ Camilo Escalona M., De Allende a Bachelet: Una Vida Política, 2012, p. 180. 
Destacamentos Populares Cinco de Abril. Esta organización realizó algunas operaciones, entre las que se cuentan asaltos a locales comerciales e interferencias de señales de televisión para difundir proclamas contra la dictadura militar ${ }^{85}$.

Hacia 1988 cuando el destino de Chile dependía del plebiscito del 5 de octubre, la mayoría de quienes habían formado parte de los Destacamentos Populares Cinco de Abril (del PS de Almeyda), realizaban trabajo político en las distintas estructuras del partido en el país.

\section{FUENTES Y REFERENCIAS BIBLIOGRÁFICAS}

\section{Fuentes orales: entrevistas}

'Arnaldo'. Empleado, militante del PS, integrante de los Destacamentos Populares Cinco de Abril. Entrevista con el autor, Estocolmo, Suecia, 2012.

'El Osito'. Empleado, ex miliciano socialista. Entrevista con el autor, Berlín, abril 2006.

'Galindo'. Comerciante, integrante del grupo socialista que se entrenaba en Cuba en septiembre de 1973. Entrevista con el autor, Valparaíso, octubre, 2006.

'Juan Miranda'. Profesor, integrante del grupo socialista que se entrenaba en Cuba en septiembre de 1973. Entrevista con el autor, Suecia, julio 1999.

'Manuel'. Empleado, ex miembro de la escolta del Presidente Salvador Allende (GAP). Entrevista con el autor, Santiago de Chile, septiembre 2006.

Prado, Juan Carlos. Empleado, ex militante del Partido Socialista. Entrevista con el autor, Santiago de Chile, mayo 2009.

'Reinaldo'. Empleado, militante del Partido Socialista. Entrevista con el autor, Buenos Aires, Argentina, octubre 2011.

Ruilova, Patricio. Comerciante, ex militante del Partido Comunista. Entrevista con el autor, Buenos Aires, octubre 2011.

Santana, Manuel. Ingeniero, militante del Partido Comunista. Entrevista con el autor, Buenos Aires, octubre 2011.

'Tato'. Empleado, ex militante del Partido Socialista. Formó parte del grupo de campesinos que en 1973 viajó a la Unión Soviética a realizar un curso de tractorista. Conversación con el autor, Santiago de Chile, julio 2009.

Valdivia, José ('Marvin'). Coronel del Ejército Popular Sandinista (EPS). Entrevista con el autor, Managua, octubre 2008.

Viciani, Orel. Cientista político, ex militante del Partido Comunista, ex diputado comunista por Iquique. Entrevista con el autor, Santiago, junio 2011.

85 'Arnaldo', entrevista con el autor, Estocolmo, julio 2012. 


\section{Fuentes escritas y referencias bibliográficas}

Álvarez, Rolando. Desde las Sombras: Una Historia de la Clandestinidad Comunista (1973-1980). Santiago: LOM Ediciones, 2003.

Apablaza Guerra, Sergio. "Recordando a un Hermano". Memoria Viva, martes 5 de abril de 2005. http://memoriaviva.net/article.php3?id_article=37.

- "Nicaragua. Julio de 1979. Recuerdos del Triunfo Guerrillero". Memoria Viva, viernes 21 de julio de 2006. http://www.memoriaviva. net/article.php3?id_article=295.

Barrios, Pedro. "Con el Brazalete Rojinegro" (Parte uno). Memoria Viva, 2005. http://www.memoriaviva.net/article.php3?id_article=5.

Blanchet Muñoz, Raúl. "En qué Están los Combatientes de Ayer. A 25 Años del Surgimiento del Frente Patriótico Manuel Rodríguez". Marcha $\mathrm{N}^{\circ} 3,5$ de diciembre de 2008.

Bonnefoy M., Pascale, Claudio Pérez S. y Ángel Spotorno L. y la Brigada 30 Aniversario de la Revolución Sandinista. Internacionalistas Chilenos en la Revolución Popular Sandinista. Santiago: Editorial Latinoamericana, segunda edición ampliada, 2009.

Bravo, Viviana. "Moscú-La Habana-Berlín: Los Caminos de la Rebelión. El Caso del Partido Comunista de Chile 1973-1986". En Elvira Concheiro, Máximo Modonesi y Horacio Crespo (eds.), El Comunismo: Otras Miradas Desde América Latina. Ciudad de México: Centro de Investigaciones Interdisciplinarias en Ciencias y Humanidades, Universidad Nacional Autónoma de México, 2007.

Coloma A., Hernán. Los Tránsfugas. Santiago: Editorial Mare Nostrum, 2010.

Cordobés, Germán (probablemente sea un seudónimo). “A 30 Años del Inicio de la Tarea Militar: 16 de Abril Día del Combatiente Internacionalista". Memoria Viva, jueves 21 de abril de 2005. www.memoriaviva.net/ article.php3?id_article $=46$.

Corvalán Lepe, Luis. De lo Vivido y lo Peleado. Memorias. Santiago: LOM, 1997.

Escalona M., Camilo. De Allende a Bachelet: Una Vida Política. Santiago: Aguilar, 2012.

Friedman V., Judith 'Tita'. Mi Hijo Raúl Pellegrin: Comandante José Miguel. Santiago: LOM, 2008.

Herreros, Francisco. Del Gobierno del Pueblo a la Rebelión Popular. Santiago: Siglo XXI, 2003.

Llona Mouat, Ismael. Los Santos Están Marchando. Santiago: Ediciones Off The Record, 2006.

Marenco, Eduardo. 'Entrevista con 'El Chiguín': Los 'Gansos Salvajes' de la EEBI”. La Prensa 10 de agosto de 2000. http://www.manfut.org/ cronologia/tachofinal.html.

Melo, Galvarino. Piel de Lluvia. Santiago: MAGO Editores, 2005.

Memoria Viva. Viernes 21 de julio de 2006. http://memoriaviva.net/article. php3?id_article=295.

Meyer, Adriana. "En Política Todo es Posible. Entrevista con Sergio Apablaza Guerra, ex Jefe del Frente Patriótico Manuel Rodríguez”. Página 12, 24 de diciembre de 2007. http://rebelion.org/noticia.php?id=60659. 
Ortega, Javier. "La Historia Inédita de los Años Verde Olivo". La Tercera (serie especial, capítulo I), Santiago, 22 de abril de 2001.

Ortega Saavedra, Humberto (general). La Epopeya de la Insurrección. Managua: LEA-Grupo Editorial, 2004.

Palma Salamanca, Ricardo. Una Larga Cola de Acero: (Historia del FPMR 1984-1988). Santiago: LOM, 2001.

Partido Comunista de Chile. "Al Partido y al Pueblo de Chile" (Santiago, 20 de diciembre de 1974). En Partido Comunista de Chile, iDesde Chile Hablan los Comunistas! Santiago: Ediciones Colo-Colo, 1976.

- "El Ultraizquierdismo, Caballo de Troya del Imperialismo" (Santiago, septiembre de 1975). En Partido Comunista de Chile, ;Desde Chile Hablan los Comunistas! Santiago: Ediciones Colo-Colo, 1976.

Peña, Cristóbal. Los Fusileros. Crónica Secreta de una Guerrilla en Chile. Santiago: Random House Mondadori S. A., 2007.

Pérez, Cristián. "Guerrilla Rural en Chile: La Batalla del Fundo San Miguel, 1968”. Estudios Públicos Nº 78 (2000a).

- "Salvador Allende, Apuntes sobre su Dispositivo de Seguridad: El Grupo de Amigos Personales (GAP)”. Estudios Públicos N 79 (2000b). "El Ejército del Che y los Chilenos que Continuaron su Lucha". Estudios Públicos № 89 (2003).

Pérez, Justiniano. GN Versus FSLN: Análisis de un Pasado Reciente. Managua: Editorial La Prensa,(2008.

Ponomariov, Boris. "Conferencia”. Revista Internacional, Praga, enero 1974.

Qué Pasa. "La Cruzada Armada del PC”, Santiago, 23 de mayo de 1988.

Quiroga, Patricio. Compañeros. El GAP: La Escolta de Allende. Santiago: Aguilar, 2001.

Reorganización del Rodriguismo. "Raúl Pellegrin y el Pensamiento del FPMR. Historia del FPMR". Santiago, 1996. www.elortiba.org/lar.html

Rojas N., Luis. De la Rebelión Popular a la Sublevación Imaginada: Antecedentes de la Historia Política y Militar del Partido Comunista de Chile y del FPMR 1973-1990. Santiago: LOM, 2011.

Salazar, Gabriel. Conversaciones con Carlos Altamirano: Memorias Críticas. Santiago: Random House Mondatori S. A., 2010.

Seoane, Juan. Los Viejos Robles Mueren de Pie: Relato Autobiográfico de un Policía Leal. Santiago: Editorial Universidad Bolivariana, 2009.

"Siete Días" (programa de la televisión mexicana). "Revolución Sandinista. La Ofensiva Final", 1979. http://www.youtube.com/watch?v=KbN0d8EQh gE\&feature $=$ related.

Suárez, Luis (editor). Manuel 'Barbarroja' Piñeiro: Che Guevara y la Revolución Latinoamericana. Bogotá: Ocean Sur, 2006.

Teillier, Guillermo. "G. Teillier sobre Combatientes Internacionalistas Chilenos". En página de internet del Partido Comunista de Chile. Santiago, martes 27 de abril de 2006. http://pcchile.cl/index2. php?option $=$ com_content $\&$ task $=$ view\&id $=328 \&$ Itemid $=51$.

Teitelboim, Volodia. Noches de Radio (Escucha Chile: Una Voz Viene de Lejos (2 tomos). Santiago: LOM, 2001. 
Televisión Nacional de Chile (TVN). "Informe Especial”, capítulo del 28 de junio de 2006.

Uliánova, Olga. “La Unidad Popular y el Golpe Militar en Chile: Percepciones y Análisis Soviéticos". Estudios Públicos, 79 (invierno 2000).

Valenzuela Levi, José Joaquín ('Comandante Ernesto’) (1987). “Otro Día Será". En Frente Patriótico Manuel Rodríguez, Manuel Cabalga de Nuevo. Santiago: 1987.

Vergara, Pablo y Sebastián Campaña. "FPMR: El Fantasma sin Cabeza". Siete $+7, \mathrm{~N}^{\mathrm{o}} 24$, agosto de 2002 .

Vidal, Hernán. Frente Patriótico Manuel Rodríguez. El Tabú del Conflicto Armado en Chile. Santiago: Mosquito Editores, 1995.

Vidal, Virginia. "Qué Fue el Frente Patriótico Manuel Rodríguez: Le Debemos su Rescate Histórico". Memoria Viva, 2005. http://www.memoriaviva. net/article.php3?id_article $=43$. 